\title{
ОСОБЕННОСТИ ПРЕПОДАВАНИЯ БУХГАЛТЕРСКОГО УЧЕТА ОБУЧАЮЩИМСЯ ПО РАЗНЫМ НАПРАВЛЕНИЯМ
}

\author{
(C) 2019 Муравицкая Наталья Константиновна \\ кандидат экономических наук, профессор Департамента учета, анализа и аудита \\ Финансовый университет при Правительстве Российской Федерации, Россия, Москва \\ E-mail:nmuravitskaya@fa.ru
}

В данной статье исследуется вопрос о подготовке кадров высшего образования в условиях цифровизации экономики. Реализация образовательных программ высшего образования должна обеспечивать получение качественных профессиональных квалификаций. Критерием оценки качества полученного образования является высококлассный специалист профессионально выполняющий свои функции. На всех этапах получения высшего образования студент должен систематически подтверждать полученные теоретические знания практическими навыками. В связи с этим необходимо актуализировать рабочие программы дисциплин. Возникает острая необходимость в штате преподавателей имеющих практический опыт и непрерывно повышающий свою квалификацию. В современном мире главным в обучении является не объем усвоенных обучающимися знаний, а способность интеллекта к быстрому освоению необходимых знаний и умений. Главной функцией образования становится формирование умений находить необходимую информацию с целью эффективного использования при выполнении своих профессиональных обязанностей.

Ключевые слова: информация, квалификация, бухгалтерский учет, инновационная деятельность, онлайн-образование, компетенции, образовательный стандарт.

В условиях цифровизации экономики возобновилась потребность в кадрах высокой квалификации, в соответствии с чем появилась потребность в практико-ориентированных образовательных программах. Следствием стало появление профилированных бакалаврских образовательных программ.

Ни для кого не секрет, что в современном отечественном образовании наблюдается ряд кризисных явлений, связанных с тем, что многие выпускники ВУЗов работают не по специальности, а отрасли реальной экономики в то же время испытывают сложности с кадровым обеспечением.

В высшем образовании присутствуют многоуровневые иерархические взаимоотношения между отдельными дисциплинами. Теоретические дисциплины, изучаемые на младших курсах, не только создают общекультурные и общепрофессиональные компетенции, работая тем самым непосредственно на модель специалиста, но и составляют необходимый базис для изучения специальных дисциплин, и именно в этом их основное предназначение (основы бухгалтерского учета, финансовых учет, финансовая отчетность, управленческий учет, анализ, аудит). Без знания базовых дисциплин невозможно продвинуться в освоении последующих специальных дисциплин, ибо студент будет буквально на каждом шагу сталкиваться с последствиями своего незнания (недопонимания). Базовые теоретические дисциплины работают на модель специалиста лишь опосредованно, фактически цель их заключается в том, что они обеспечивают возможность освоения последующих специальных дисциплин.

Обратимся к одному существенному моменту, с которым приходится сталкиваться профессорско-преподавательскому составу. Дело в том, что в образовательной деятельности работа производится не с абстрактной моделью «обучающегося вообще», а с конкретным студентом, как правило только закончившим школу, отличающегося от уже обучающегося или выпускника ВУЗа, и приходится формально требовать выработки компетенций даже у первокурсников (готовность к кооперации с коллегами, к работе на общий результат, владение навыками организации и координации взаимодействия между людьми, контроля и оценки эффективности деятельности других). Давая обучающимся соответствующие задания, преподаватель может выяснить только то, что студенты могут решить именно эти задания и не более того. 
Проанализировав современные образовательные стандарты и высказывания ведущих специалистов в области образования (профессиональный преподавательский состав), можно констатировать, что действующие образовательные стандарты мало приспособлены к какому-либо практическому применению в образовательной деятельности, эффективной подготовке кадров для народного хозяйства. Назрела необходимость пересмотреть принципы формулировок компетенций при формировании ФГОС. Заявляя об определенной компетенции, необходимо предоставить возможность ее диагностирования. Состав курсов в образовательных программах должен формироваться с учетом междисциплинарного подхода. Научно обоснованная последовательность освоения учебных дисциплин должна обеспечить освоение образовательных компетенций, необходимых для конкретной квалификации. Назрела необходимость возврата УМО объединяющих профессионалов-единомышленников, имеющих высокий потенциал для повышения содержательного уровня образовательных стандартов. Одним из важнейших условий успешного развития цифровой экономики является кадровое обеспечение процессов на всех уровнях. Именно поэтому в учебных заведениях необходимо проводить соответствующие работы по уточнению учебных программ, учебных планов, основных образовательных программ и форм обучения. Назрела необходимость ориентации при разработке учебных планов и особенно рабочих программ дисциплин на специализацию слушателей. Для разработки эффективных учебных программ должно быть налажено тесное взаимодействие образовательных учреждений с организациями (работодателями). Целесообразно выделить блок базовых знаний для всех специальностей, которые предусматриваются бакалавриатом. В этом случае при изучении бухгалтерского учета нет необходимости в подробном изложении всех направлений учетного процесса, необходимо дать понятие основных этапов бухгалтерской работы:

- учетная политика и ее роль в формировании учетно-аналитической информации;

- план счетов бухгалтерского учета, первичные документы и учетные регистры;

- основные формы отчетности и их содержание.

При этом основное внимание должно быть уделено последнему блоку, поскольку отчетность является основным источником информации для принятия решения как внешними пользователями отчетности так и внутренними на любом уровне и по всем функциональным направлениям деятельности организации, так как в современном обществе необходимо уметь хотя бы в общих чертах понимать финансовую информацию, носителем которой является бухгалтерский учет.

На старших курсах бакалавриата необходимо выделить дисциплину, которая наиболее полно раскрывает особенности учета и отчетности применительно к специальности. Это определяет какие разделы учетной политики, объекты учета необходимо раскрывать более подробно при чтении лекций, ведении практических занятий и организации самостоятельной работы студентов. Именно при изучении данной дисциплины необходимо показать единство учета, анализа и контроля по направлениям типичным для конкретных специалистов работающих в: производстве, строительстве, торговле, бюджетной сфере, туризме и т.д.

Модели обучения в современном мире постоянно видоизменяются. В концепции образования знания должны определяться не как некое накопление, а как средство формирования системы знаний с целью эффективного использования для успешной практической деятельности и развития интеллектуальных возможностей обучаемых.

В ходе встречи с ректорами российских высших учебных заведений премьер-министр Дмитрий Медведев подчеркнул, что внедрение онлайн-курсов в процессе традиционного образования является магистральным вектором развития онлайн-обучения. По мнению премьер-министра Дмитрия Медведева, необходимо шире внедрять смешанный формат обучения.

Одной из задач подготовки кадров является воспитание навыков работы с информацией, включая ее поиск, систематизацию и обработку, который может быть получен только при самостоятельной работе студента, что предполагает разработку кейсов, творческих заданий, дискуссий и других ситуационных материалов которые студент должен выполнить по данным конкретной организации, желательно при непосредственном контакте с будущим работодателем, а не по абстрактным материалам. Особая роль заключается в использовании студентами 
видео материалов- лекций, учебных фильмов. Рекомендации по использованию онлайн-ресурсов связаны с простотой и реалистичностью их потребления. Онлайн-консультации дают возможность своевременно оказывать помощь студентам заинтересованным в углубленном изучении дисциплины и выполнении научной работы.. Цель самостоятельной работы состоит в поиске и приобретении новых и закреплении и углублении уже полученных знаний и навыков, в том числе навыков самостоятельной работы не только с учебным материалом, но и самостоятельно найти путь решения новой для него задачи. Самостоятельное направление работы становится особенно важно в условиях цифровизации экономики, поскольку в этом случае самостоятельная работа студента может быть выполнена на основе поиска необходимой информации с использование современных технологий, для повышения обоснованности выводов, интерпретирования полученной информации во взаимосвязи.

Проанализировав ряд учебных планов, можно заметить в них отсутствие последовательности изучения дисциплин. Но, как показывает практика, нельзя приступать к изучению практической части без основательного изучения теоретических основ дисциплины.

Например, учебный план содержит изучение таких дисциплин как- управленческий учет и анализ, а бухгалтерский учет являющийся базой для этих дисциплин отсутствует. Другой учебный план содержит перечень следующих дисциплин - финансовый и управленческий учет, анализ финансовой отчетности, а дисциплины финансовая отчетность не предусмотрено и т.д. Такая ситуация отрицательно сказывается на понимании студентами изучаемого материала.

Содержание рабочих программ по дисциплинам курса должно отражать специфику предполагаемой деятельности выпускника, что в дальнейшем положительно скажется на его деятельности.

В оснащении дисциплины необходимо, по возможности, предусмотреть кейс-технологии в образовании, это важнейший инструмент, который позволяет обучающимся применить имеющиеся теоретические знания для решения практических задач. Важную проблему при чтении курса представляет понятийный аппарат.

В рабочих программах дисциплин по бухгалтерскому, финансовому, управленческому учету, анализу, аудиту и соответственно при изложении материалов лекции и практических занятий необходимо использовать единую терминологию, так как в противном случае у обучающихся может возникнуть недопонимание и некачественное восприятие информации. Цифровая экономика изменит и учет, и аудит, и анализ. Внутри учета преобразуются взаимоотношения финансового и управленческого учета. Обязательной составляющей становится и интегрированная отчетность.

Цифровизацией вызвано взаимодействие учебной сферы с другими областями экономики: маркетингом, менеджментом, финансами и др., так как она принесла глобальную связанность всего со всем, создающую всеобщее взаимодействие.

Процесс подготовки бакалавров, магистров и специалистов постоянно обсуждается в научном и профессиональном обществе. Дискуссии возникают при разработке федеральных и собственных образовательных стандартов, между теоретиками и практиками. Необходимо учитывать и мнение работодателей, так как подготовка профильных специалистов должна учитывать экономическую обстановку в стране. Образовательные стандарты должны быть взаимозависимыми. Актуальна прямая и обратная связь между образовательными учреждениями и работодателем. Образовательные стандарты требуют привлечения практиков, но не всегда это обеспечивает высокое качество подготовки специалистов. Целесообразно организовать обмен опытом между студентами, преподавателями и квалифицированными специалистами с целью выявления проблем, которые упускаются в процессе преподавания учебных дисциплин. Механическое внедрение в образовательный процесс практиков влечет за собой риск принятия обучающимися стереотипов хозяйственной или управленческой деятельности конкретных предприятий. Несомненна и польза стажировки преподавателей у работодателей в организация, так как нередка ситуация, когда преподаватель не имеет практического опыта деятельности, в связи с чем предлагаемый в ходе лекции или практического занятия материал не может заинтересовать обучающихся.

Одна из задач преподавателя - заинтересовать студентов в научной работе. В профессиональной литературе ведутся дискуссии в части теории и практики бухгалтерского учета. Вовле- 
чение студентов в дискуссию дает возможность ознакомить их с историей развития бухгалтерского учета с его совершенствованием в течение многих столетий, за которые сформирован свой специфический понятийный аппарат: счета, дебет, кредит, баланс, проводка, контировка и др. Предмет и метод бухгалтерского учета.

Австралийский ученый М. Граффикин (M. Graffikin) пришел к выводу, что учет ближе всего находится к группе социальных наук эволюционирующего направления «Учет - это «система мышления», разработанная людьми для оказания помощи людям в принятии решений и влияний друг на друга».
Бухгалтерский учет не зря называют языком бизнеса. Бухгалтерский баланс и другие формы отчетности являются главными источниками информации о финансовом положении любой организации. Каждый работник организации так или иначе пользуется информацией, полученной в рамках бухгалтерского учета. Задача преподавателя заключается не только в передаче студентам системы знаний, но и создания условий для формирования умений находить, оценить и эффективно использовать информацию для выполнения профессиональных задач, самообучаться.

\section{Библиографический список}

1. Федеральный закон от 29.12.2012 № 273-ФЗ «Об образовании в Российской Федерации»

2. Сизов В.С. Инновации в образовании, Вопросы новой экономики № 4(28)2013

3. Михайлова Г.В., Потехина Е.В. Особенности методики преподавания бухгалтерского учета, Г.А. Бахчисарайцева - представителя московской учетной школы Учет, анализ, аудит Т.5,№ 52018

4. Деменьтьев Д.В. Взаимосвязь образовательных и профессиональных стандартов, Учет, анализ, аудит Т.5,№ 32018

5. Развитие онлайн-образования остается государственным приоритетом, Качество образования № 3 июль-сентябрь 2018 